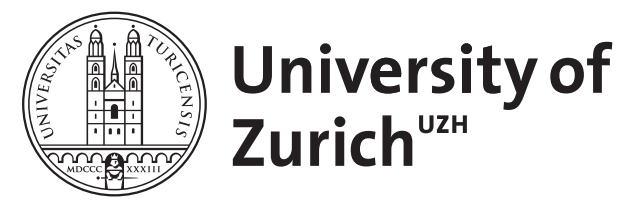

\title{
Challenges and practices of interviewing business elites
}

\author{
Ma, Shenghui ; Seidl, David ; McNulty, Terry
}

\begin{abstract}
Interviews are an important method for studying a wide range of phenomena, especially those that directly involve members of the so-called business elite, which typically includes CEOs, top managers, and boards of directors. While it is necessary to get close to these actors and their settings for gaining valuable research insights, interviews are challenging interactions to accomplish. Even when one has negotiated access, members of the business elite are typically time-constrained, knowledgeable, used to being in a dominant position, and visible in the public domain and involved in impression management. These particularities pose distinctive challenges for collecting rich and authentic empirical material about important organizational, managerial, and societal matters. Drawing on our own experience, as well as the literature on qualitativeinterviewing and elites research, we discuss how different research designs and interview practices can help deal with these challenges.
\end{abstract}

DOI: https://doi.org/10.1177/1476127020980969

Posted at the Zurich Open Repository and Archive, University of Zurich

ZORA URL: https://doi.org/10.5167/uzh-197660

Journal Article

Published Version

Originally published at:

Ma, Shenghui; Seidl, David; McNulty, Terry (2021). Challenges and practices of interviewing business elites. Strategic Organization, 19(1):81-96.

DOI: https://doi.org/10.1177/1476127020980969 


\section{Challenges and practices of interviewing business elites}

Strategic Organization

$1-16$

(C) The Author(s) 2020

Article reuse guidelines: sagepub.com/journals-permissions DOI: $10.1177 / 1476127020980969$ journals.sagepub.com/home/soq

\author{
Shenghui Ma \\ Fudan University, China
}

\title{
David Seidl
}

University of Zurich, Switzerland

\section{Terry McNulty \\ University of Liverpool, UK}

\begin{abstract}
Interviews are an important method for studying a wide range of phenomena, especially those that directly involve members of the so-called business elite, which typically includes CEOs, top managers, and boards of directors. While it is necessary to get close to these actors and their settings for gaining valuable research insights, interviews are challenging interactions to accomplish. Even when one has negotiated access, members of the business elite are typically time-constrained, knowledgeable, used to being in a dominant position, and visible in the public domain and involved in impression management. These particularities pose distinctive challenges for collecting rich and authentic empirical material about important organizational, managerial, and societal matters. Drawing on our own experience, as well as the literature on qualitative interviewing and elites research, we discuss how different research designs and interview practices can help deal with these challenges.
\end{abstract}

\section{Keywords}

business elites, data collection, interviewing, qualitative methods

\section{Introduction}

Due to their roles at the apex of organizations, business elites, such as CEOs, top executives, and boards of directors, are of particular interest to management research and interviews are a key method for collecting data about them. Compared with other methods, interviews have the distinctive advantage that they involve actual encounters with people generally considered as difficult to

\section{Corresponding author:}

Shenghui Ma, School of Management, Fudan University, Shanghai 200433, China.

Email: shenghuima@fudan.edu.cn 
reach with the potential to generate information that is novel and insightful (Natow, 2020) about what elites say and do; the settings in which they operate; their motivations, assumptions, meanings; and their relationships, decisions, and actions. In this regard, interviewing is a way to understand elite agency and their interactions, which are often widely dispersed across time and space. Interviewing is also complementary to other methods for studying elites (Maclean et al., 2006), and for these reasons likely remain an important approach for studying business elites (e.g. Garg and Eisenhardt, 2017; Ma and Seidl, 2018; McNulty and Pettigrew, 1999; Pye, 2001) and a key method for studying a wide range of phenomena, including corporate governance, upper echelons, strategy, and organizational change (Hertz and Imber, 1995; Langley and Meziani, 2020; McNulty et al., 2013; Pettigrew, 1992).

While it is powerful for advancing research, interviewing business elites is widely recognized to be challenging, which might undermine the quality of data collected. Business elites are typically time-constrained, knowledgeable, used to being dominant in interaction, often visible public figures with reputations at stake, and hence involved in impression management. These particularities pose various challenges for interviewing and generating high-quality empirical material and research. In this article, we will discuss these challenges of interviewing business elites and practical ways of dealing with them. It will draw both on existing studies and on the literature about interviewing elites as well as our own experience. We suggest that challenges in elite interviews can be addressed and alleviated through research design and the actual conduct of interview interactions. On the level of research design, the arrangements of interviews in existing studies are shown to differ along two dimensions: on the one hand, studies can be focused on elites as individuals (e.g. Brown et al., 2019; Maclean et al., 2012a) or their firms (e.g. Garg and Eisenhardt, 2017; Kisfalvi et al., 2016), and on the other hand, researchers can conduct one-off interviews (e.g. Maclean et al., 2012b; McNulty and Pettigrew, 1999) or serial interviews, that is, interviewing the same people repeatedly over time (e.g. Ma and Seidl, 2018; Smith et al., 2019). By acknowledging the influence of research designs, we identify important nuances and opportunities of dealing differently with the particular challenges of elite interviewing at the outset of a study.

Regarding the actual conduct of interviewing, we discuss practices that can be useful for dealing with the challenges in elite interviewing. Rather than repeating the plentiful and generic textbook advice that is available about conducting interviews (e.g. Rubin and Rubin, 2011), we focus on those issues and related practices that are directly related to the challenges of interviewing elites. We highlight (1) how creating the time for an engaging and worthwhile interview experience for the interviewee can help deal with the challenge of time constraints, (2) how flexibly using an interview structure can help deal with attempts by elite actors' to dominate the interview situation, (3) how establishing trust and credibility can help deal with the challenge of impression management, and (4) how researchers can leverage publicly available information to deal with challenges of knowledgeability, domination, and impression management.

We show how both the choice of research design and the practices of conducting interviews may help overcome the challenges of elite interviews to maximize the potential of generating rich and authentic data, which for us is the key quality criterion of data collection. While replicability has been put forward as a quality criterion for elite interviews (Aguinis and Solarino, 2019), we do not focus on it as it has been shown to be misleading and even harmful for qualitative research (Pratt et al., 2020). As Pratt et al. (2020) stressed, "replication misses the point of what the work seeks to accomplish" (p. 1).

\section{Challenges and potentials of elite interviews}

Interviews allow researchers to obtain from business elites invaluable information and insights, which are often unavailable using other methods. CEOs, top executives, and board members 
typically have experience and knowledge of leading and governing companies and can provide information about how things typically work at the apex of their organization. Moreover, they can provide details of what they are doing in their specific organization in ways that may illuminate wider societal and institutional matters of economy, finance, corporations, policy, and regulation. In addition, interviewing can help researchers capture how business elites construct narratives about their actions, associations, and effects. Elite interviewing is therefore consistent with rationales for using qualitative data in studies of strategic organization, whether that be to capture individuals' subjective experiences and interpretations; understand processes and causal mechanisms; lend vividness, concreteness, and richness to an abstract idea or model; or examine words and language as linguistic phenomena (Graebner et al., 2012).

However, whether one realizes the great potential of elite interviews depends on the quality of empirical material generated from the interviews. There is a vast literature on qualitative research in general and interviewing in particular that covers an array of philosophical and practical considerations, such as the different forms of qualitative interviews (Alvesson, 2003; Roulston and Choi, 2018); practicalities, challenges, and limitations of interview design and conduct (Langley and Meziani, 2020; Roulston, 2010); and alternative criteria of qualitative research quality (Pratt et al., 2020; Tracy, 2010). Informed by these debates, we regard richness and authenticity as core quality criteria of interview data, which are crucial for developing high-quality qualitative research. Interview data needs to be rich in terms of its breadth and depth in capturing interviewees' experiences, perspectives, and related contexts (Kvale and Brinkmann, 2009; Ritchie et al., 2013; Rubin and Rubin, 2011). Also it needs to be authentic, that is, containing reliable and genuine information (Kvale and Brinkmann, 2009; Rubin and Rubin, 2011). Rich and authentic data enables researchers to develop "deeper, fuller conceptualizations of those aspects of our subjects' lives we are most interested in understanding" (Miller and Glassner, 1997: 103).

However, compared with other interviewees, business elites pose distinct challenges for collecting rich and authentic data. We discuss four challenges here. First, business elites are subject to high demands for their attention and highly constrained on time. Thus, they (and their diary managers) are particularly conscious of using their time efficiently. It is a challenge of both initial access negotiation and conduct during the interview to ensure that business elites allocate sufficient time to the interview so as to enable an in-depth interview (Ostrander, 1993). The difficulty of access has been widely recognized by previous researchers (Harvey, 2011; Hirsch, 1995; Useem, 1995), but as Empson (2018) highlights, even when access has been granted, business elites may not allocate sufficient time and attention on the day of the interview, which can restrict the richness of data collected.

Second, social scientists are often warned about acting according to their own theoretical logic and trained to approach interviews using lay language and leaving sufficient space for subjects' views, surprises, and anomalies (Hochschild, 2009). Such warnings are valid, but a particularity about business elites is that through experience and education, including management education, they are often well versed in the language of well-known concepts, theories, and "best-practices" in business and management. As a result, interviews with business elites are frequently laced with their language and understanding of concepts of business, management leadership, and governance. When faced with interviewers they may regard as "business theorists," they may feel inclined to speak "scientifically" and respond with textbook-type answers to questions. In this regard, it can be difficult for researchers to avoid theoretical ideas and concepts, relying only on lay language. The challenge for the interviewer is therefore to use their concepts and language as a resource for developing a conversation that engages with both the "general" and the "particular" of their knowledge and experience.

Third, by virtue of their position, business elites are used to being in positions of power, and this may carry over into a dominant disposition when interacting with people inside and outside their 
organizations. If they use their position and status to dominate the interview, it can cause a power imbalance between themselves and the researcher (Empson, 2018; Mikecz, 2012), so it is important that researchers act prior to, and during the interview, to avoid a power asymmetry developing in the interview situation (Briggs, 2001) to the extent that the interviewer loses control over the agenda and course of the interview.

Fourth, elite business actors tend to be visible in the public domain and thus are particularly concerned with their reputation. Indeed, what they say and do can have a material effect not only on their reputation but also on that of their companies and others involved. As a result, they tend to be particularly careful about what they say and its potential reputational and other material effects. Researchers should expect the interviewee to be used to, and good at, engaging in impression management. After all, "[i]mpression management is integral to the day-to-day operations of executives" (Maclean et al., 2012b: 24). They often have extensive experience in being interviewed by media and are astute with protecting the images of themselves or their firms (Kvale and Brinkmann, 2009). Their habit and skills of impression management constitute a challenge for collecting authentic data.

Of course, these challenges can be turned into unique opportunities for generating empirical material. That business elites are often particularly knowledgeable about management concepts and even research can be leveraged as an opportunity for data collection. Such knowledge can enable them to "co-construct" (Cunliffe and Scaratti, 2017: 40) insights and even co-theorize from their experiences with the researcher. Our experience, indeed, is much of the enjoyment of interviewing business elites rests in the development of concepts and theories in the course of conversation. Elite knowledge and impression management are challenges, but they are also resources which can be leveraged by researchers to uncover concepts and test constructs in the field during interviews. For example, aspects of the model of "strategy involvement" (McNulty and Pettigrew, 1999) emerged during questioning about managerial hegemony and board impotence in relation to strategy. Couplets of "engaged but non-executive," "challenging but supportive," and "independent but involved" were identified through interviews with company directors as central to understanding behaviors that boards and directors use to create accountability (Roberts et al., 2005). In an ongoing study on strategic decision-making, two of the authors mentioned to a CEO that his role in decision-making differs from the Burgelman model (Burgelman, 1983) in which top managers usually act as selectors of strategic ideas developed by lower level employees. The CEO was able to engage with the comment by explaining why that model does not work well for a firm like his, and thus he had to bring "big ideas" from his external network. His explanation was intriguing for us to develop an article on the role of top management in developing strategic initiatives.

Second, any tendency by elite actors to be dominant in interaction can also be turned to good effect by an interviewer exploiting that business elites are used to talking about their views, experiences, and feelings and often assume others are interested in hearing from them (Ostrander, 1993). Open questions can work well with elite actors as they are particularly able to respond at length rather than give short answers (e.g. Ostrander, 1993). In our own research, we often found that they proactively provided examples and explanations without being asked to do so-other interviewees usually were more passive in responding to questions, and we often had to ask more probing questions in order to get details. In interviews, it is common for elite actors to bring up entirely new issues or angles that we had not thought of and thus not asked about. Elites are typically confident to suggest questions or issues that should be addressed by the researchers. One striking example was the experienced board member who suggested, as part of a research interest in what constitutes an effective board, that more attention should be paid to boards' readiness to handle a hostile takeover attempt, especially ones that appear late on a Friday afternoon before a long weekend with a public holiday attached to it. By way of another example, in one interview 


\begin{tabular}{|c|c|c|}
\hline \multirow{4}{*}{ Serial } & Individual-based, Serial & Firm-based, Serial \\
\hline & $\begin{array}{l}\text { Focus of research: } \\
\text { Processual, temporal phenomenon around an } \\
\text { individual }\end{array}$ & $\begin{array}{l}\text { Focus of research: } \\
\text { Processual, temporal phenomenon around a } \\
\text { firm }\end{array}$ \\
\hline & $\begin{array}{l}\text { Feature of sample: } \\
\text { Repeated interviews with a relatively large } \\
\text { number of individuals from different firms }\end{array}$ & $\begin{array}{l}\text { Feature of sample: } \\
\text { One or a small number of firms with repeated } \\
\text { interviews with several people from each firm }\end{array}$ \\
\hline & $\begin{array}{l}\text { Example studies: } \\
\text { Mantere \& Whittington, 2020; Smith et al., } \\
2019\end{array}$ & $\begin{array}{l}\text { Example studies: } \\
\quad \text { Garg \& Eisenhardt, 2017; Ma \& Seidl, } 2018\end{array}$ \\
\hline \multirow{5}{*}{ One-off } & Individual-based, One-off & Firm-based, One-off \\
\hline & $\begin{array}{l}\text { Focus of research: } \\
\text { Patterns of individual activities or narratives }\end{array}$ & $\begin{array}{l}\text { Focus of research: } \\
\text { Patterns of firm-level activities or narratives }\end{array}$ \\
\hline & $\begin{array}{l}\text { Feature of sample: } \\
\text { One-off interviews with a large number of } \\
\text { individuals from different firms }\end{array}$ & $\begin{array}{l}\text { Feature of sample: } \\
\text { One or a small number of firms with one-off } \\
\text { interviews with several people from each firm }\end{array}$ \\
\hline & $\begin{array}{l}\text { Example studies: } \\
\text { Brown et al., 2019; McNulty \& Pettigrew, } \\
1999\end{array}$ & $\begin{array}{l}\text { Example studies: } \\
\quad \text { Mantere \& Vaara, } 2008\end{array}$ \\
\hline & Individual-based & Firm-based \\
\hline
\end{tabular}

Figure I. Typical research designs of interview-based research on business elites.

with a CEO, two of the authors asked him about steps he had taken to change the firm. Yet in answering our question, he told us that we had to understand that new CEOs like him were expected to introduce change. Thus, even when you think everything is going well, you need to introduce changes - at least symbolically — in order to be taken seriously as a new CEO. His response made us aware of the symbolic role of change in establishing CEO authority.

Third, elite actors' impression management can also be turned into an opportunity, particularly when the researcher is interested in the interviewee's narratives or stories and how they rationalize and construct social reality (e.g. Brown et al., 2019; Mantere and Whittington, 2020). In this type of research, impression management can be understood as an essential part of the storytelling that the researcher is trying to capture. As managing and building impressions is common to the elite actors' positions and roles, one can analyze stories told during the interview for what they suggest about interactions among elites, for example, how elite members describe trying to influence "elite" peers in and around boards (Pettigrew and McNulty, 1995). The impression management in storytelling during the interview can be extremely valuable for researchers to gain insight into "official" and "unofficial" versions of events (Roberts et al., 2005).

\section{Research designs for elite interviews}

Various designs have proven to be effective in generating rich and authentic data through elite interviews. From the existing literature, we have identified four ideal-typical research designs that have yielded high-quality research results (Figure 1). These research designs are differentiated along two dimensions. First, the research designs differ in terms of whether the research is firm-based or individual-based. In other words, a study can be focused on specific firms or specific elite individuals. Second, these designs differ in terms of whether the research is based on one-off interviews or 
a series of interviews with the same individuals over time. In the following, we will first introduce the four research designs highlighting their particular merits, and then discuss how the different aspects of each design can help dealing with the described challenges of elite interviews.

\section{A typology of research designs and their particular merits}

The first type of research design can be referred to as "individual-based, one-off" interviews. Studies adopting this design are often interested in members of a particular group of business elites, for example, non-executive, independent directors. The purposive selection of interviewees is to achieve a sample of individuals according to, for example, their role and position at the highest levels of companies. This design is particularly suited for revealing prominent patterns of action, experience, and narrative across an elite grouping and involves interviews on the basis of a common role or group membership, such as a company director and board member. For example, by interviewing 108 non-executive directors (NEDs) operating on boards of financial times stock exchange (FTSE) 350 UK companies, McNulty and Pettigrew (1999) revealed the extent to which these actors talk about their relative power and influence to influence strategy, given conflicting portrayals of boards in the literature at the time of boards as either "pawns of management" or strategic decision-making groups. The empirical material collected about differences in director and board contributions to strategy enabled them to model their interpretations of how NEDs are involved in strategic decisions in different ways and with different effects, revealing assumptions and existing theories to be partial and limited as explanations of board involvement in strategy. The "individual-based, one-off" interview design is also helpful in identifying typical narratives employed by business elites. For example, interviewing 31 business school deans in the United Kingdom, Brown et al. (2019) revealed different ways in which deans constructed their identity narratives in order to defend the meaning of their work.

As these examples show, studies adopting this design often focus on revealing practices and narratives common among a particular group of business elites. This design allowed the researchers in those studies to collect empirical material to develop theoretical concepts that capture similarities and differences within elite behavior, influence, and identity. For such purposes, studies often include a relatively large number of interviewees from a particular group of business elites, including interviewees who not only have a role in common but perform the role across various settings or industries or from different backgrounds. The main rationale behind this design is that a large and diverse group of interviewees can better reveal what is general and what is particular among a "sample" of respondents, and what are typical and prominent patterns of similarity and difference among elite behaviors, views, and discourses out there in relation to the specific role of interest (Fassin and Van Rossem, 2009).

The second type of design can be referred to as "individual-based, serial" interviews. While it also focuses on individual actors rather than organizations as wholes, it differs from the first type in that the informants are interviewed repeatedly over time. The purpose is often to track how the actions, thoughts, and narratives of individual elite actors develop over time. For example, in their

study of how Black women succeed in the C-suite, Smith et al. (2019) conducted two waves of interviews with 59 Black female executives. After the first wave of interviews focusing on the executives' "career progression and personal history, relationships and sponsorship, and perceptions of career opportunities and risks," the second wave of interviews was focused on capturing their "career trajectories and career changes in the intervening seven years" (Smith et al., 2019: 1715). Similarly, through repeated interviews with 19 senior managers, Mantere and Whittington (2020) studied how they build their identity as strategist. The repetition allowed the authors to track the changes and developments of their identity narratives in the course of becoming 
strategists. As these two examples show, this type of study is powerful in revealing how executives' actions, perceptions, and narratives develop over time, which can be difficult to capture with oneoff interviews.

The third type of design refers to "firm-based, one-off" interviews. In contrast to individualbased interviews, studies that adopt this design tend to be more interested in firm-level phenomena; they focus specifically on how elite actors behave and interact with others in specific firms, aiming to understand their influence on firm-level actions and consequences. Therefore, they are typically conducted in the context of a case-study design - often including other sources of data as well, such as documents and observations (Eisenhardt, 1989). These studies typically include multiple interviewees from each case firm in order to generate a more comprehensive understanding of the elites' activities within the firm and how they interact with the case context. In their study of strategy discourse, for example, Mantere and Vaara (2008) interviewed between two and five top managers, as well as other members, from each of their 12 case companies. Instead of individual narratives (e.g. Dameron and Torset, 2014), Mantere and Vaara (2008) were interested in how multiple actors in the same company construct organizational narratives about strategy and their effects on participation in the strategy process. Due to the effort required to study each firm, the total number of case firms tends to be limited to a dozen. However, this approach is powerful for studying multilevel phenomena within organizations and how business elites' activities and discourses are embedded in their organizational contexts.

The fourth type of design can be referred to as "firm-based, serial" interviews. Studies adopting this design are often interested in the firm-level processes of how critical events or activities unfold over time. The focus on firm-level dynamics and the influence of case contexts are similar to those of firm-based, one-off interviews. However, in contrast to one-off interviews, serial ones enable researchers to better capture potential developments and trajectories in an organization over time by interviewing the same people multiple times to generate a dynamic view of the process of interest. For example, in their study of strategic decision processes in four high-tech firms, Garg and Eisenhardt (2017) conducted four to five waves of interviews with the same board members in each firm, which resulted in 23 interviews on average for each company. In another study, which was focused on capturing how new CEOs form their top management teams (TMTs), Ma and Seidl (2018) adopted a similar research design conducting on average 17 interviews in each of the eight companies they studied. They interviewed several elite actors (particularly, CEO and top executives) in each company multiple times over the new CEO's first 2 years and the CEO for 6-10 times. Data collected by such longitudinal designs can be particularly useful for generating process models, such as of CEO-board interaction (Garg and Eisenhardt, 2017) or of TMT formation (Ma and Seidl, 2018) as discussed in the above examples.

\section{How choices of research design help deal with the challenges of elite interviewing}

As discussed above, the individual-based design typically involves interviewing a large number of elite actors from different firms, over a period of months or years. The volume of interviewing coupled with the length of time moving between field and data can help alleviate the challenges regarding elites' potential domination and impression management in interviewing. After having interviewed several elite actors with similar roles (e.g. CEOs), researchers will become more familiar with any tendency to dominate the interview interaction and develop their approach and knowledge to counter them. Moreover, the individual-based design can also help deal with the challenges associated with the elite actors' concern for reputation and impression management, as the large number of interviewees associated with the design makes it easier to guarantee anonymity in eventual publications. For example, McNulty and Pettigrew (1999) list everyone involved in the 
study while still protecting individual confidentiality in relation to the details of data. Notwithstanding that the interviews touched on sensitive topics such as politics and power in the boardrooms of major public limited companies (PLCs) and in relation to some high-profile publicly reported events, all the participants agreed to be listed in the reporting of the study aiding the transparency of the study and credibility of its coverage of a particular segment of the business elite at that time. Also due to the typically large sample, undue generality and inauthenticity on the part of respondents can be exposed and overcome in developing and publishing the findings of the study.

Firm-based design provides opportunities for dealing with other challenges in elite interviewing. First, it can be easier to gain elite actors' interest in and time commitment for the research project when access to a firm and its managerial elite is secured for the research to be focused on firm-level phenomena. Indeed, the elite actors may perceive it as an opportunity for gaining academic feedback or advice on difficult issues (e.g. strategic change) in their companies. Second, that firm-based design typically involves interviewing multiple individuals within the same firm can help deal with potential problems caused by elite actors' knowledge about the research subject: gathering information from other members of the firm allows the researcher to counter weaknesses of self-reported data, triangulate useful information, and develop questions about specific events or instances, all practices which can alleviate the possibility that elite interviewees provide only generalized accounts that lack depth and detail. Third, the information collected from others in the firm can also be used to counter the interviewee's potential domination of the interview situation. For example, the researcher can use descriptions or views gathered from other interviewees (while preserving their anonymity) to capture and compare an interviewee's view on something heard elsewhere by listening for difference or even asking outright: "In some of our interviews we have heard of this to be an important issue. Could you tell me your view of it?" Elite interviewees often become less dominant and more open when they receive questions regarding specific facts or views that would otherwise not be known to externals. Fourth, information collected from multiple individuals in the same firm can help recognize and deal with an interviewee's impression management as elite interviewees realize that they are not the only ones who are providing detailed and authentic information in the interviews.

Related to the choice of one-off versus serial interview designs, we also find different advantages in dealing with the outlined challenges. In particular, in one-off interview designs it is often easier to secure the elite interviewee's time commitment and attentional engagement, simply because it requires less time from the individual elite actors, compared with the repeated interviews in the serial designs. Apart from that, analogous to our argument about individual design discussed above, the larger number of elite interviewees can be leveraged to learn elite actors' tendency of domination and develop tactics to counter it in later interviews with others. The large sample associated with this design also makes it easier to guarantee anonymity.

By contrast to the one-off design, serial designs can help alleviate some of the challenges in other ways. While serial interviewing means that the elite actor will have to invest even more time in interviews, perhaps exacerbating the challenge of time constraints, our experience shows that elite interviewees often develop their commitment to the research project over the course of the series of interviews. Often, it takes time for them to realize the benefit that such interviews can provide, such as systematically stimulating their reflection. For example, at the beginning of our research (Ma and Seidl, 2018), we did not fix with the case companies how many times we wanted to interview the CEOs. This made it easier for the CEOs to agree to participate in the initial interviews. Only after the first interview did we ask whether the CEOs would be open to be interviewed again, explaining that this would allow us to track particular issues or developments. Such time requests might have not been granted if we had asked the CEO for many rounds of interviews at 
the very beginning of the study. Moreover, serial interviews afford greater scope for researchers to probe deeper into events and developments related to the elite actor. Such information can help researchers distinguish between the elite's "empirical descriptions" and "theoretical reflections." Multiple interviewing of the same persons can also enable researchers to prepare even more informed questions. In serial-design studies, researchers can learn about the elites' tactics of domination as well as how to counter them in later interviews. In addition, the challenge of elite actors' concern for reputation and impression management can be more easily dealt with as interviewing the same person multiple times helps build trust and thus reduces the elite actors' concern for impression management. Researchers can place more sensitive questions in later interviews when trust and rapport with the elite actor has been developed.

\section{How interview practices can help deal with challenges of elite interviewing}

We have discussed above how research designs can help deal with the challenges of elite interviewing. However, collecting high-quality data also requires us to deal with these challenges in each interview. Drawing on existing studies and our own experience, we will discuss a range of interview practices that have proven particularly helpful in handling the described challenges of elite interviews.

\section{Creating the time for an engaging and worthwhile interview experience}

To alleviate the threat of time for an interview being restricted or curtailed, notwithstanding what may have been agreed when negotiating access in the first instance, it is important to prepare to conduct the interview in a way that serves the purpose of the research and also affords the interviewee an experience they feel is a worthwhile use of their time. Our experience shows that when elite actors appreciate the interview experience, they tend to keep or even extend the time for the interview. This is particularly the case when the researcher actively guides the interaction to create an engaging conversation where the interviewee feels sufficiently curious about the research, interested in the topic, stimulated by the conversation, and even challenged by the interview questions.

From our experience, we recognize that senior business leaders are in a position whereby they lack individuals with whom they can privately yet openly talk about the challenges they face. It is not uncommon to leave an interview and receive the complement on departure, delivered in a tone of slight surprise of "actually I quite enjoyed the conversation." A CEO in our study (Ma and Seidl, 2018) explained why he appreciated the research interviews:

It's very difficult to talk openly within the organization, so you need to have kind of an external partner to talk to . . . if you ask a CEO of I would say a level of maybe, you know, between 4000 and 15000 employees, then it's probably that they have very few people they really talk to openly. . . . [that's why for] an opportunity like this, you kind of take [it].

McNulty and Pettigrew (1999) also experienced interviews as occasions for non-executive members to discuss privately, and in ways they would not do publicly, their concerns and even insecurities about their role influence and effectiveness as well as their experiences of reputational damage by association with corporate scandal and failure.

To help create the conditions for such an experience, we have found it helpful to highlight the purpose, interest, and potential benefits of the research at the negotiation of access and then reinforce these at the outset of the interview. Setting the tone is relevant to conducting all interviews 
but especially so for serial interviews when a person is being asked for several interviews over time. In the study by Ma and Seidl (2018), three CEOs expressed that the serial interviews were like a series of therapy sessions providing an opportunity for a systematic reflection on what they did and why they had made certain decisions. For example, one of the CEOs in our study told us,

I did [the interviews] because I think it's a good thing you do and it's interesting, you know, to read it afterwards, but most of all it's self-reflection. So it's kind of like working-by you asking questions, it's working things through and trying to reflect what you do and why you do it because you ask. You have to start thinking. So it's kind of like a therapy.

\section{Establishing researcher trust and credibility to safeguard reputation}

An attraction of interviews with business elites is the potential to discuss important business matters including past and real-time decisions and to develop research insights and interpretations using information that is not otherwise available or developed in the public domain. However, because business elites are often visible figures and identifiable in the public domain, data provided are of interest to others and if used without care can compromise the interviewees and their organizations. We have found that guaranteeing confidentiality and non-attribution of empirical material is a critical condition of conducting an in-depth interview. Particularly for those elite members who are not familiar with research interviews (compared with journalistic interviews), they may not understand how the information they provide will be used in eventual publications. They may even treat researchers like journalists (Kvale and Brinkmann, 2009). During interviews in which sensitive issues are discussed and private views are being divulged, it is not unusual for the interviewee to have moments when they convey some concern with what they are about to say when talking about a specific topic, setting, or indeed relevant others. They may indicate this directly, but often one can also sense a change in tone, body language, or eye contact. In such circumstances, when sensing a discomfort on their part it is important to reassure them that the data will be used only in an anonymous way or even offer to turn off any recording device or suspend note-taking. Overall, in our careers we have been surprised at how elites have been willing to be recorded. However, one does need to be prepared to suspend recording or note-taking to enable people to talk, often taking the initiative to do so and not necessarily waiting to be asked. Recent examples of this occurred when one company director of their own volition revealed in interview with one of us that they had worked with an individual who became a central figure in a major corporate collapse. The interviewee wanted to talk about their experience of that individual and indications of that person's style and approach to work early in their career, which they thought relevant to explaining how and why that person later engaged in an abuse of power and responsibility with considerable public consequences.

Building researcher trustworthiness to have those kinds of conversation is a process that precedes demonstrating professional integrity throughout the interview and what you will do with the empirical material after the interview. At the point of negotiating access, demonstrating personal and institutional adherence to research ethics can help researchers begin to establish themselves as a trustworthy and reliable professional in the eyes of the interviewee. Indeed, for a recent study (Keay et al., 2020), McNulty found that company directors and members of the judiciary were reassured, rather than put off by heightened university requirements for written consent and other ethical research practices administered prior to the interview taking place.

Total respect for the confidence of interviewees is critical, but it can be tested when elite networks are tight, as they can be across, for example, boards of listed companies, and when people work together in the same companies. Elite interviewees are sometimes interested to hear about 
what other interviewees within the same or other companies have said. Being dominant and powerful individuals, they may ask the researchers about information that has been collected, even though the principles of confidentiality and anonymity were made clear before the interview. Empson (2018) stressed that resisting their requests and sticking to the principle of confidentiality can actually win elite actors' trust by demonstrating the professionalism of the researcher. Sometimes, researchers may feel pressure or even be tempted to reveal what they know from interviewing others in order to open up the interviewee, and it is important for the researcher to take particular effort not to breach confidences and disclose the source of information even when it does not cause any harm, as such behaviors can undermine the researcher's trustworthiness and research ethics.

When conducting the interview, it is a challenge to strike the right balance of trust and rapport while maintaining critical distance (Empson, 2018; Mikecz, 2012). To accomplish the balance may mean displaying empathy when elite actors share their difficulties and frustrations during the interview. For example, in our research on new CEOs (Ma and Seidl, 2018), CEOs sometimes shared their frustrations with changing their TMTs due to various constraints. We showed our empathy and understanding of their situations in ways such as echoing that we had observed similar frustrations in our interviews with other CEOs. Our experience shows that such subtle reactions were useful for building a trust relationship which can also help in alleviating the potential for elite domination of interviews.

\section{Flexibly using an interview structure to deal with the challenge of domination}

In order to collect rich and authentic interview data, it is important for the interviewer to strike the right balance between flexibility and control, given that business elites are used to exerting authority over others (Richards, 1996). In this regard, it has proven helpful to set an interview structure that can be flexibly used to counter any attempt by elite actors to take control over the interview process. The most common form of such a structure is the semi-structured interview guide, typically consisting of a number of predefined themes and questions (Hirsch, 1995). Apart from guiding the interviewer in the choice of questions, the interview guide provides an effective controlling device during the interview.

We usually make it clear at the beginning of an interview that we have prepared a list of key questions. Signaling that we have a structure is important because it helps manage the interviewee's expectation that we have some sort of control over what to talk about. However, we would then let the conversation go where the elite interviewees wanted to take it so long as it is productive for the purposes of the research. During the interview, it is a matter of judgment as to how to deal with "unexpected turns or digressions that follow the informant's interests or knowledge" (Johnson and Rowlands, 2012: 107), which may be productive in leading the conversation to what is important to the interviewee. In this regard, the interview is open not closed, and the interviewer is humble enough to afford due space and time to listen (Helin, 2013) to the person, yet not so deferential as to lose control of the course of the interview. Time can also be used with the schedule should it be necessary to assert control to stem an unproductive direction of conversation and move to other questions and themes by, for example, saying "that's helpful to know. I see that we have only 15 minutes left, can we move to the next point which is about . ..."

Moreover, the interview structure can be designed not only for which topics to cover in the interview but also which aspects to probe for greater depth and detail. For example, in an ongoing study on how top managers process strategic issues, Ma and Seidl used a structure that requires the interviewee to talk about each strategic issue covering details such as where was the idea from? who was involved? and how did it develop? However, this is not to suggest that one should follow 
a structure rigidly during the interview, which is often counterproductive (Empson, 2018), but rather to use the structure flexibly to counter the potential domination of elite interviewees. In addition to an interview guide, there are many other structuring devices that one may employ. For example, in their interviews with directors, McNulty and Pettigrew used a list of substantive matters of business and governance items generated inductively from initial pilot interviews with directors (Pettigrew and McNulty, 1995) to change the pace and focus of the conversation and ensure that for all interviews some time was devoted to gathering data to gauging the relative power and influence of company directors across a range of substantive business and governance matters. An inductively derived and scaled list of items was used for approximately 20 minutes in each interview and afforded the interviewer time and control within the context of the interview with resulting data that provided a breadth of perspective on board power and influence that complemented the depth derived from the other parts of the interview process which probed influence in substantive matters in more detail.

\section{Leveraging public information to deal with challenges of knowledge, domination, and impression management}

Business elites are particularly visible people in the public domain. In these days of greater media reporting and public datasets, CEOs, board members, and top executives are easily identifiable in terms of their personal characteristics, career histories, affiliations, and views on matters including the affairs of their organizations. The publicly available information is a resource that researchers can leverage as advanced preparation (Denscombe, 2003). From our experience, we concur with the view that the effectiveness of elite interviews hinges on the knowledgeability of the interviewees (Natow, 2020). As observed earlier, time for interview is a precious resource and there is a skill to using what can be obtained elsewhere from the public domain in the interview to make the best use of interview time to focus discussion, probe, challenge, and augment questioning. It also enables researchers to ask questions about actual instances and events, which requires the elite interviewees to provide empirical details. Utilizing public information to ask well-informed questions, demonstrate a good knowledge of the elite actor's context, and ask about actual examples of action and circumstance can help deal with three challenges highlighted above-knowledgeability, domination, and impression management.

For example, for the study by Pettigrew and McNulty (1995) and McNulty and Pettigrew (1999), considerable time was spent in the days before an interview gathering and analyzing publicly available data about NEDs' multiple board positions and company events and decisions that they may have been a party to as a board member. Not all of this information was used, but it was available to recall, if necessary, when seeking to delve deeper into questioning about their experiences of board decision-making, board culture, and the challenges each management presented to the board by way of exercising power and influence. This knowledge was critical in enabling the discussion to reach beyond prior theoretical or popularized generalities of directing companies that board members might tend to rely on in their responses to the particulars of board and company contexts.

Moreover, researchers can make use of such information to reduce the elite interviewee's information power and therefore their potential domination. In particular, Mikecz (2012), in his study on political elites, highlights that asking well-informed questions can help the researcher reduce power asymmetries in the interview. We also found it helpful to signal to the interviewee that we know a lot about them and their working context. For example, when a CEO interviewee said that it had been a stressful time recently, we responded by asking, "is that because of the performance decline in the North American market?" We got to know about the performance issue in the media before the interview. While we were not particularly interested in that, we responded in this way to 
show that we were aware of what is going on. Learning the elites' vocabulary and jargon can be helpful as well. Empson (2018: 62) shared that for interview preparation, "I read the trade press to learn about style as well as substance" because adopting elite interviewees' style and discourse is helpful for reducing elites' domination by signaling the researcher's familiarity with their professional world.

In addition, using public information to ask informed questions, challenge their answers, and indicate researchers' knowledge can also help researchers undermine the elite actors' tendency of impression management. For example, in their study on the strategic role of independent directors, McNulty and Pettigrew (1999) focused the conversation on "critical incidents" (Flanagan, 1954) that they had learned about in the public media in order to ensure that the interview went beyond self-serving generalized accounts. Indeed, once raised, they often relished the opportunity to talk in a fuller way about an issue that they felt had not necessarily been adequately covered in the public domain through journalistic accounts and other media commentaries. Asking well-informed questions about critical incidents affords credibility, the ability to "triangulate" information (Natow, 2020), and the possibility to reach beyond superficial generalities and impression management.

\section{Conclusion}

In this article, we have discussed key challenges and related practices of collecting rich and authentic interview data from business elites. While the delineation and operationalization of elites is a long-recognized research challenge and there are different views as to who constitutes business elites (for an overview, see Harvey, 2011; Pettigrew, 1992), we focus on those who occupy upper level positions of organizations, including CEOs, senior managers, and board members who have attracted intensive attention in strategy and organization studies. Ultimately, we are interested in the particularities of these kinds of actors and how they impose specific challenges for research interviews.

Our article has two main implications. First, our discussion can help early career researchers realize the potential of interviews with business elites. Our article can help researchers become aware of the challenges and, more importantly, the choices regarding research design and practices of interviewing that can be helpful for dealing with them. To be sure, experience is helpful, and early career researchers may thus want to collaborate with more experienced colleagues initially. Second, our essay contributes to the discussion on how to evaluate qualitative studies in management research (Jarzabkowski et al., 2014; Pratt et al., 2020), with a special focus on elite interviews. While several scholars have focused on the criteria of data analysis and findings (Gioia et al., 2013; Jarzabkowski et al., 2014; Pratt et al., 2020), we have focused here on data collection that seems specifically challenging when interviewing elites compared with other actors. Editors and reviewers may pay particular attention to how a study has dealt with these challenges in data collection. Moreover, these challenges and how to deal with them may depend on one's research design, that is, individual- versus firm-based and one-off versus serial interviews. Apart from highlighting the challenges of elite interviews, we have also tried to show that interviews provide a particularly powerful and rewarding approach for collecting unique data on the people at the top of the business world.

\section{Acknowledgements}

The authors thank the co-editors Paula Jarzabkowski and Ann Langley and the two anonymous reviewers for their constructive comments and encouragement throughout the review process. They also thank Annie Pye and Richard Whittington for their helpful feedback on the earlier versions of this paper. 


\section{Funding}

The author(s) declared the following potential conflicts of interest with respect to the research, authorship, and/or publication of this article: This study received funding from National Natural Science Foundation of China (No. 72002037) and Swiss National Science Foundation (No. 100018_169436/ 1).

\section{ORCID iDs}

Shenghui Ma (iD https://orcid.org/0000-0002-0918-5684

David Seidl (iD https://orcid.org/0000-0002-0368-196X

Terry McNulty (iD https://orcid.org/0000-0002-9846-5062

\section{References}

Aguinis H and Solarino AM (2019) Transparency and replicability in qualitative research: The case of interviews with elite informants. Strategic Management Journal 40(8): 1291-1315.

Alvesson M (2003) Beyond neopositivists, romantics, and localists: A reflexive approach to interviews in organizational research. Academy of Management Review 28(1): 13-33.

Briggs (2001) Interviewing, power/knowledge and social inequality. In: Gubrium JF and Holstein JA (eds) Handbook of Interview Research: Context and Method. Thousand Oaks, CA: SAGE, pp. 910-922.

Brown AD, Lewis MA and Oliver N (2019) Identity work, loss and preferred identities: A study of UK Business School Deans. Organization Studies. Epub ahead of print 27 June. DOI: 10.1177/0170840619857464.

Burgelman RA (1983) A process model of internal corporate venturing in the diversified major firm. Administrative Science Quarterly 28(2): 223-244.

Cunliffe AL and Scaratti G (2017) Embedding impact in engaged research: Developing socially useful knowledge through dialogical sensemaking. British Journal of Management 28(1): 29-44.

Dameron S and Torset C (2014) The discursive construction of strategists' subjectivities: Towards a paradox lens on strategy. Journal of Management Studies 51(2): 291-319.

Denscombe M (2003) The Good Research Guide: For Small-Scale Social Research Projects, 2nd edn. Buckingham: Open University Press.

Eisenhardt KM (1989) Building theories from case-study research. Academy of Management Review 14(4): $532-550$.

Empson L (2018) Elite interviewing in professional organizations. Journal of Professions and Organization 5(1): 58-69.

Fassin Y and Van Rossem A (2009) Corporate governance in the debate on CSR and ethics: Sensemaking of social issues in management by authorities and CEOs. Corporate Governance: An International Review 17(5): 573-593.

Flanagan JC (1954) The critical incident technique. Psychological Bulletin 51: 327-358.

Garg S and Eisenhardt K (2017) Unpacking the CEO-board relationship: How strategy-making happens in entrepreneurial firms. Academy of Management Journal 60(5): 1828-1858.

Gioia DA, Corley KG and Hamilton AL (2013) Seeking qualitative rigor in inductive research: Notes on the Gioia methodology. Organizational Research Methods 16(1): 15-31.

Graebner ME, Martin JA and Roundy PT (2012) Qualitative data: Cooking without a recipe. Strategic Organization 10(3): 276-284.

Harvey WS (2011) Strategies for conducting elite interviews. Qualitative Research 11(4): 431-441.

Helin J (2013) Dialogic listening: Toward an embodied understanding of how to "go on" during fieldwork. Qualitative Research in Organizations and Management: An International Journal 8(3): 224-241.

Hertz R and Imber JB (1995) Studying Elites using Qualitative Methods. Thousand Oaks, CA: SAGE.

Hirsch PM (1995) Tales from the field: Learning from researchers' accounts. In: Hertz R and Imber JB (eds) Studying Elites Using Qualitative Methods. Thousand Oaks, CA: SAGE, pp. 72-80.

Hochschild JL (2009) Conducting intensive interviews and elite interviews. Workshop on Interdisciplinary Standards for Systematic Qualitative Research. Available at: https://scholar.harvard.edu/jlhochschild/ publications/conducting-intensive-interviews-and-elite-interviews 
Jarzabkowski P, Bednarek R and Lê JK (2014) Producing persuasive findings: Demystifying ethnographic textwork in strategy and organization research. Strategic Organization 12(4): 274-287.

Johnson J and Rowlands T (2012) The interpersonal dynamics of in-depth interviewing. In: Gubrium JF, Holstein JA, Marvasti AB, et al. (eds) The SAGE Handbook of Interview Research: The Complexity of the Craft, 2 edn. Thousand Oaks, CA: SAGE, pp. 99-114.

Keay A, Loughrey J, McNulty T, et al. (2020) Business judgment and director accountability: A study of caselaw over time. Journal of Corporate Law Studies 20(2): 359-387.

Kisfalvi V, Sergi V and Langley A (2016) Managing and mobilizing microdynamics to achieve behavioral integration in top management teams. Long Range Planning 49: 427-446.

Kvale S and Brinkmann S (2009) Interviews: Learning the Craft of Qualitative Research Interviewing. Thousand Oaks, CA: SAGE.

Langley A and Meziani N (2020) Making interviews meaningful. Journal of Applied Behavioral Science 56(3): 370-391.

Ma S and Seidl D (2018) New CEOs and their collaborators: Divergence and convergence between the strategic leadership constellation and the top management team. Strategic Management Journal 39(3): 606-638.

Maclean M, Harvey C and Chia R (2012a) Reflexive practice and the making of elite business careers. Management Learning 43(4): 385-404.

Maclean M, Harvey C and Chia R (2012b) Sensemaking, storytelling and the legitimization of elite business careers. Human Relations 65(1): 17-40.

Maclean M, Harvey C and Press J (2006) Business Elites and Corporate Governance in France and the UK. Basingstoke: Palgrave Macmillan.

McNulty T and Pettigrew A (1999) Strategists on the board. Organization Studies 20(1): 47-74.

McNulty T, Zattoni A and Douglas T (2013) Developing corporate governance research through qualitative methods: A review of previous studies. Corporate Governance: An International Review 21(2): 183-198.

Mantere S and Vaara E (2008) On the problem of participation in strategy: A critical discursive perspective. Organization Science 19(2): 341-358.

Mantere S and Whittington R (2020) Becoming a strategist: The roles of strategy discourse and ontological security in managerial identity work. Strategic Organization. Epub ahead of print 6 March. DOI: $10.1177 / 1476127020908781$.

Mikecz R (2012) Interviewing elites: Addressing methodological issues. Qualitative Inquiry 18(6): 482-493.

Miller J and Glassner B (1997) The "inside" and the "outside": Finding realities in interviews. In: Silverman D (ed.) Qualitative Research. London: SAGE, pp. 99-112.

Natow RS (2020) The use of triangulation in qualitative studies employing elite interviews. Qualitative Research 20(2): 160-173.

Ostrander SA (1993) "Surely you're not in this just to be helpful": Access, rapport, and interviews in three studies of elites. Journal of Contemporary Ethnography 22(1): 7-27.

Pettigrew A and McNulty T (1995) Power and influence in and around the boardroom. Human Relations 48(8): 845-873.

Pettigrew AM (1992) On studying managerial elites. Strategic Management Journal 13: 163-182.

Pratt MG, Kaplan S and Whittington R (2020) Editorial essay: The tumult over transparency: Decoupling transparency from replication in establishing trustworthy qualitative research. Administrative Science Quarterly 65(1): 1-19.

Pye A (2001) A study in studying corporate boards over time: Looking backwards to move forwards. British Journal of Management 12(1): 33-45.

Richards D (1996) Elite interviewing: Approaches and pitfalls. Politics 16(3): 199-204.

Ritchie J, Lewis J, Nicholls CM, et al. (2013) Qualitative Research Practice: A Guide for Social Science Students and Researchers. London: SAGE.

Roberts J, McNulty T and Stiles P (2005) Beyond agency conceptions of the work of the non-executive director: Creating accountability in the boardroom. British Journal of Management 16(s1): S5-S26.

Roulston K (2010) Considering quality in qualitative interviewing. Qualitative Research 10(2): 199-228. 
Roulston K and Choi M (2018) Qualitative interviews. In: Flick U (ed.) The SAGE Handbook of Qualitative Data Collection. London, SAGE, pp. 233-249.

Rubin HJ and Rubin IS (2011) Qualitative Interviewing: The Art of Hearing Data. Thousand Oaks, CA: SAGE.

Smith AN, Watkins MB, Ladge JJ, et al. (2019) Making the invisible visible: Paradoxical effects of intersectional invisibility on the career experiences of executive black women. Academy of Management Journal 62(6): 1705-1734.

Tracy SJ (2010) Qualitative quality: Eight "Big-Tent" criteria for excellent qualitative research. Qualitative Inquiry 16(1): 837-851.

Useem M (1995) Reaching corporate executives. In: Hertz R and Imber JB (eds) Studying Elites Using Qualitative Methods. Thousand Oaks, CA: SAGE, pp. 18-39.

\section{Author biographies}

Shenghui $\mathrm{Ma}$ is an associate professor of Business Administration at the School of Management at Fudan University. His research focuses on the CEO succession process, CEO advice seeking, and top management team dynamics. Address: School of Management, Fudan University, Shanghai 200433, China. [email: shenghuima@fudan.edu.cn]

David Seidl is a full professor of Organization and Management at the University of Zurich. His main areas of research are strategy as practice, top management team dynamics, and routine dynamics. Address: Department of Business Administration, University of Zurich, Plattenstrasse 14, CH-8032 Zurich, Switzerland. [email: david.seidl@uzh.ch]

Terry McNulty is associate dean and professor of Management and Corporate Governance at the University of Liverpool Management School. He researches governance and board effectiveness by focusing on director behavior and relationships. Address: Management School, University of Liverpool, Chatham Street, Liverpool L69 7ZH, UK. [email: t.h.mcnulty@liverpool.ac.uk] 